\title{
Validity and reliability of the Chinese version of the Insulin Treatment Appraisal Scale among primary care patients in Hong Kong
}

\author{
KP Lee *
}

\section{A B S T R A C T}

Introduction: Patients with diabetes mellitus often delay insulin initiation and titration due to psychological factors. This phenomenon is known as 'psychological insulin resistance'. Tools that identify psychological insulin resistance are valuable for detecting its causes and can lead to appropriate counselling. The Insulin Treatment Appraisal Scale was initially developed for western populations and has been translated and validated to measure psychological insulin resistance in Taiwan (Chinese version of the Insulin Treatment Appraisal Scale, CITAS). The current study examined the prevalence of psychological insulin resistance and the validity of the C-ITAS in a local population.

Methods: This cross-sectional study involved 360 patients with diabetes mellitus from a governmentfunded general out-patient clinic who completed the C-ITAS questionnaire. The total C-ITAS score was compared for patients with psychological insulin resistance and those without, and the internal consistency and test-retest reliability of the C-ITAS were calculated. An exploratory factor analysis was

This article was published on 3 Jun 2016 at www.hkmj.org. used to identify factors within the C-ITAS.

Results: The prevalence of psychological insulin

resistance was $44.9 \%$. The internal consistency of the scale was high (Cronbach's alpha $=0.78$ ). The test-retest reliability was positive with all C-ITAS questions (0.294-0.725). The mean C-ITAS score was significantly higher among patients with psychological insulin resistance than those without (42.42 vs $35.78 ; \mathrm{P}<0.001$ ). The exploratory factor analysis, however, failed to identify the two clear factors identified in the original validation study.

Conclusions: The C-ITAS appears to be a feasible and potentially useful tool for identifying psychological insulin resistance, but additional validation or translation is required before it can be widely used clinically.

Hong Kong Med J 2016;22:306-13

DOI: $10.12809 / \mathrm{hkmj} 154737$

KP Lee *, FRACGP, MSc Mental Health (CUHK)

Department of Family Medicine and Public Health Unit, Kowloon West Cluster, Hospital Authority, 118 Shatin Pass Road, Hong Kong

* Corresponding author: ineric_2000@yahoo.com.hk

This paper was presented at the Hospital Authority Convention, 18-19 May 2015, Hong Kong.

New knowledge added by this study

- The Chinese version of the Insulin Treatment Appraisal Scale (C-ITAS) is a potentially useful and reliable tool to understand patients' underlying reasons for psychological insulin resistance (PIR).

- Further validation of C-ITAS is needed.

Implications for clinical practice or policy

- Understanding patients' PIR can lead to appropriate and patient-centred counselling.

- Validation of C-ITAS can facilitate a comparison of local PIR studies with those in other countries.

\section{Introduction}

Type 2 diabetes mellitus (DM) is a prevalent and increasingly common disease worldwide. ${ }^{1}$ It is estimated to affect $10 \%$ of the Hong Kong (HK) population (approximately 700000 people). ${ }^{2}$ Achieving satisfactory DM control during the early disease course can reduce DM-induced microvascular and macrovascular complications (ie the 'legacy effect'). ${ }^{3,4}$ These benefits were maintained in patients in a tight DM-control group even though their glycosylated haemoglobin (HbA1c) level became similar to those in the control group after the end of the United Kingdom Prospective Diabetes
Study. ${ }^{4}$ It was proposed that a 'reverse legacy effect' also persists: "intensive glycaemic intervention started late in the natural course of diabetes seems disappointingly ineffective in limiting cardiovascular events" 5,6 Very tight control may even result in mortality. ${ }^{7,8}$ Therefore, achieving tight HbA1c control early via lifestyle changes and the use of medications including insulin is important.

Because of the progressive nature of DM, most patients eventually require insulin. ${ }^{9}$ Despite robust evidence of the benefits of early strict HbA1c control, patients often delay insulin initiation and titration. In a UK study, $50 \%$ of patients with DM delayed 
insulin initiation despite suboptimal control for 5 years, regardless of the presence of complications. ${ }^{10}$ Their reluctance to initiate insulin use $\mathrm{e}^{10-12}$ and its subsequent titration ${ }^{13}$ is known as 'psychological insulin resistance' (PIR). The prevalence of PIR has been estimated to be higher in Singapore $(70.6 \%)^{11}$ than in western countries (approximately 20\%$40 \%){ }^{12}$ A HK survey of 97 participants found a similarly high prevalence of PIR (72.1\%). ${ }^{14}$ Previous studies conducted in western countries have identified several factors that can lead to PIR. ${ }^{11-13}$ These reasons might differ in Asian countries, however. ${ }^{15,16}$ Recently, a local primary care research group developed a scale, Chinese Attitudes to Starting Insulin questionnaire, to identify barriers to insulin initiation in insulin-naïve patients with DM. ${ }^{16}$ These investigators found that Asian patients might be more affected by the availability of social support and that cultural differences might also play a role. For example, Chinese patients are more likely to combine western medical treatments with traditional Chinese medicine ${ }^{17}$ and might believe that hypoglycaemic agents cause renal toxicity. ${ }^{18}$

Doctors, particularly primary care physicians, can be insensitive to patients' psychological needs; physicians often fail to recognise psychological needs ${ }^{19}$ and might incorrectly identify the reasons for a patient's PIR. ${ }^{20,21}$ Identifying one's psychological needs might be hindered in HK due to short consultation times (lasting an average of 5-7 minutes per consultation). A limited number of longer sessions may be offered to DM patients with difficult glycaemic control, but the time limit would be 10 to 14 minutes. Therefore, a quick tool to help identify PIR and its underlying causes might help general practice physicians optimise care for their patients with DM. ${ }^{12}$ The Insulin Treatment Appraisal Scale (ITAS) was developed for this purpose. ${ }^{22}$ The Chinese version of the ITAS (C-ITAS) was validated in Taiwan, ${ }^{23}$ and has been used in Taiwan ${ }^{15}$ to investigate the underlying causes of PIR. Validating C-ITAS scores might enable direct comparisons of data between local and international studies. The C-ITAS might also be used to help local primary care clinicians identify PIR and offer appropriate counselling. The ITAS is sensitive to changes in PIR throughout the course of DM. ${ }^{24}$

This study is the first to be conducted in HK to examine the prevalence of PIR and the validity and reliability of the C-ITAS in our local population.

\section{Methods}

This research has been approved by the Research Ethics Committee at Kowloon West Cluster, Hospital Authority.

\section{Participants}

Participants were recruited from a government-

\section{胰島素治療評估量表（中文版）在基層醫療層面 上的效度和信度 \\ 李錦培}

引言：糖尿病患者往往因心理因素而抗拒啟動或延遲胰島素治療, 這 種現象被稱為「心理性胰島素抵抗」。能有效評估糖尿病患者的心理 性胰島素抵抗的工具有助偵測抵抗原因, 為患者提供適當的輔導。胰 島素治療評估量表（ITAS）最初為西方國家的糖尿病患者而設, 後來 於台灣被翻譯加以驗證得出ITAS中文版。本研究探討心理性胰島素抵 抗的比率, 以及ITAS中文版的有效性。

方法: 在這橫斷面研究中, 於一所獲政府資助的普通科門診診所求診 的360名糖尿病患者填寫了 ITAS中文版問卷。按填寫好的問卷, 我們 比較具心理性胰島素抵抗的組別與沒有的組別的ITAS得分, 並計算 ITAS中文版問卷的內部一致性和重測可靠性。利用探索性因素分析找 出ITAS中文版問卷的因素結構。

結果：心理性胰島素抵抗的比率為 $44.9 \%$ 。TAS中文版問卷的內部一 致性信度高（Cronbach's alpha信度系數為0.78）。這問卷中所有問題 的重測信度為正值（信度系數為0.294至0.725）。具心理性胰島素抵 抗的組別的問卷平均得分比沒有的組別明顯較高（信度系數為42.42 比35.78；P<0.001）。然而, 探索性因素分析未能確定在原來驗證研 究中兩個確定的因素結構。

結論：ITAS中文版問卷似乎是識別心理性胰島素抵抗的一個可行和有 效的工具, 但在臨床上廣泛應用前須進行額外的驗證或翻譯。

funded primary care general out-patient clinic in HK from July to September 2013. Written consent was obtained when the participants were approached by the research assistant. The investigator's contact information was given to each participant if they had concerns after the administration of the questionnaire. Patients who fulfilled the following criteria were recruited: (1) diagnosed with type $2 \mathrm{DM}$ as defined by the World Health Organization ${ }^{25}$ for $\geq 6$ months; (2) aged 30 years or above; (3) of Chinese ethnicity; (4) able to communicate effectively in Cantonese or Mandarin; and (5) had the mental capacity to provide informed written consent. The exclusion criteria were severe sensory deficits, severe mental illness (eg dementia, psychosis, or mental retardation), or any other health condition that compromised the ability to comprehend and complete the questionnaire. The required sample size was calculated from the estimated prevalence rate of PIR in the primary care setting. To achieve a 95\% confidence interval with a margin of error of $5 \%$ and an estimated $70 \%$ prevalence of PIR among patients with DM in public primary care, ${ }^{11,14}$ the required sample size was estimated to be 312 patients. To compensate for the predicted $20 \%$ refusal rate, at least 390 patients were recruited.

A list of DM patients who would attend the clinic the next day was obtained daily. From that list, 
40 patients were randomly selected by computer ( 25 in the morning and 15 in the afternoon). A reminder was set in the clinical computer system such that clinic staff were alerted once the patient attended his or her appointment. The procedure was repeated until the number of patients recruited exceeded 390, which was checked at clinic closing time.

Patients were encouraged to complete the questionnaire unaided because the C-ITAS is selfadministered. Because the majority of patients who attend public primary care clinics are of lower socioeconomic status and education level, those who had difficulty completing the questionnaire were assisted by research assistants who were trained by the principal investigator.

Each patient was asked whether he or she was willing to have insulin started or titrated upon his or her case doctor's suggestion. The response options included "strongly unwilling", "unwilling", "might consider it", "willing", and "very willing". Demographic data were collected, and clinical data (eg the presence of DM complications, insulin use, and control of DM and lipid levels) were retrieved from a computer database.

\section{Insulin Treatment Appraisal Scale}

The ITAS is a 20-item instrument that contains 16 negative and four positive statements that appraise insulin treatment. Each statement is ranked using a 5-point Likert-type scale from 1 to 5. Positive scores are reversed to allow for summation. The total possible score ranges from 0 to 80 . A higher score signifies a more negative appraisal of insulin. The ITAS was developed for clinical use to measure PIR. ${ }^{22}$ No cut-off score is used to diagnose PIR. Of those who completed the clinical interview, 26 were selected for phone interview 2 to 4 weeks later to examine test-retest reliability. Because of the lack of a written language difference between Taiwan and HK, the validated C-ITAS was used with the permission of the Taiwan research group.

\section{Statistical analyses}

The C-ITAS was examined for its internal reliability using Cronbach's alpha, the test-retest reliability was assessed using Pearson's correlation of test scores and retest scores, and construct validity was assessed using an exploratory factor analysis (EFA) [using Oblimin rotation as this was used in the original development study of ITAS ${ }^{22}$. Patients who answered "strongly unwilling" or "unwilling" to the question "Would you agree to start or titrate insulin treatment if advised by your case doctor?" were classified as having PIR. Descriptive statistics were used to describe the prevalence of PIR. Each C-ITAS item was dichotomised as "unwilling"

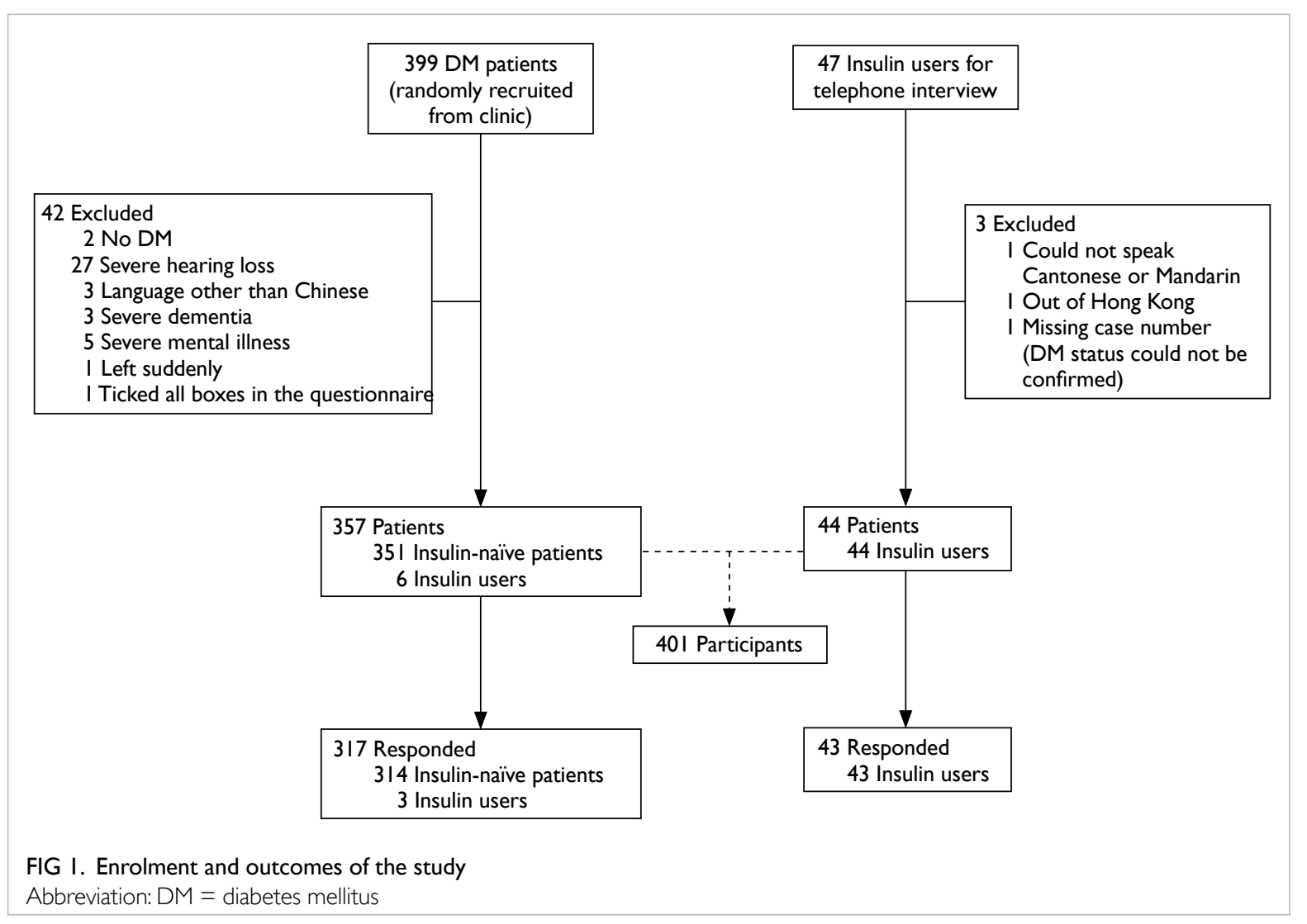


(scores of 1 and 2) or "neutral/willing" (scores of 3 to 5); this dichotomy was created to assess the difference between patients with and without PIR. The responses of the patients with or without PIR were compared using a Chi squared test.

\section{Results}

\section{Participants}

A total of 399 patients with DM were randomly selected from the clinical database and approached by the research team (Fig 1). Of them, 42 patients were excluded due to the following circumstances: two patients were incorrectly diagnosed with DM; 27 had severely impaired hearing not compensated for with the use of hearing aids; three spoke languages other than Cantonese or Mandarin; eight had severe psychiatric illness such as dementia, psychosis, or mental retardation; one left at the beginning of the interview when called into a consultation room; and one was excluded for checking all boxes of the questionnaire.

In addition to the insulin-naïve patients with DM who were recruited as outlined above, all of the current insulin users who were not interviewed during the above period ( 47 patients) were invited to participate in this study and were interviewed over the phone; of whom three were excluded for the following reasons: one could not speak Cantonese or Mandarin, one was out of HK during the interview period, and one questionnaire was invalid due to a missing subject case number.

The overall response rate was $89.8 \%(n=360)$ : $89.5 \%(\mathrm{n}=314)$ for the insulin-naïve patients and $92.0 \% \quad(n=46)$ for the insulin users. Other demographic data are shown in Table 1.

A total of $12.8 \%(n=46 / 360)$ of participants were insulin users. Patients with HbA1c $\geq 7 \%$ ( $\geq 53$ $\mathrm{mmol} / \mathrm{mol} ; 21.6 \%$ ) were more likely to be on insulin than those with $\mathrm{HbA} 1 \mathrm{c}<7 \%(<53 \mathrm{mmol} / \mathrm{mol} ; 2.9 \%$; $\mathrm{P}<0.001)$. The HbA1c level was not significantly associated with the presence of DM complications in the current study. Of all participants, $96.3 \%$ received DM complication screening within 2 years, which was a nurse-led clinical service to screen for DM complications and provide counselling.

Non-respondents were significantly older (mean age $=72.32$ vs 67.17 years, $t$ test: $\mathrm{P}<0.001$ ), less likely to agree to titrate insulin (for current insulin users), and less educated (91.7\% educated up to primary level vs $68.9 \%$; Chi squared test; $\mathrm{P}=0.004)$. The differences with regard to the other demographics, including DM complication rate, insulin use status, marriage, work, family income, and gender were not significant.

The prevalence of PIR was $44.9 \%$ (141/314; $95 \%$ confidence interval [CI], 39.4\% to $50.4 \%$ ) in insulinnaïve patients; in contrast, the PIR rate was $6.8 \%$ $(3 / 44 ; 95 \% \mathrm{CI},-0.64 \%$ to $14.24 \%)$ in current insulin users.

\section{The questionnaire}

The internal consistency of the C-ITAS questionnaire was high, with Cronbach's alpha of 0.78 . The original ITAS was designed to have 16 negative and four positive statements. Cronbach's alpha was calculated separately for the negative and positive statements, yielding values of 0.812 and 0.738 , respectively. Within the negative statement scale, removing two negatively stated questions individually, including Q1, "Insulin signifies failure with pre-insulin therapy", and Q18, "Taking insulin causes family/ friends to be more concerned" improved the overall Cronbach's alpha to 0.819 and 0.825 , respectively.

Of the 20 individual questions within the C-ITAS, answers to 17 questions were significantly

TABLE I. Demographic information of patients

\begin{tabular}{|c|c|c|}
\hline & No. of patients & $\%$ \\
\hline \multicolumn{3}{|l|}{ Response rate } \\
\hline Overall & $360 / 401$ & 89.8 \\
\hline Insulin users & $46 / 50$ & 92.0 \\
\hline Insulin-naïve patients & $314 / 351$ & 89.5 \\
\hline \multicolumn{3}{|l|}{ Demographics } \\
\hline DM for $>10$ years & $161 / 356$ & 45.2 \\
\hline \multicolumn{3}{|l|}{ Family income (HK\$) } \\
\hline$\leq \$ 10000$ & $238 / 352$ & 67.6 \\
\hline$<\$ 5000$ & $132 / 352$ & 37.5 \\
\hline Female & $216 / 360$ & 60.0 \\
\hline \multicolumn{3}{|l|}{ Education } \\
\hline No formal education & $76 / 350$ & 21.7 \\
\hline Primary school level & $165 / 350$ & 47.1 \\
\hline Tertiary level or above & $19 / 350$ & 5.5 \\
\hline Married & $241 / 358$ & 67.3 \\
\hline Retired & $271 / 359$ & 75.5 \\
\hline \multicolumn{3}{|l|}{ Control } \\
\hline $\mathrm{HbA} 1 \mathrm{c} \leq 7 \%$ & $195 / 360$ & 54.2 \\
\hline $\mathrm{LDL} \leq 2.6 \mathrm{mmol} / \mathrm{L}$ & $218 / 360$ & 60.6 \\
\hline $\mathrm{LDL} \geq 3.5 \mathrm{mmol} / \mathrm{L}$ & $41 / 360$ & 11.4 \\
\hline \multicolumn{3}{|l|}{ Complications } \\
\hline Presence of microalbuminuria/proteinuria & $58 / 360$ & 16.1 \\
\hline eGFR by MDRD $<60 \mathrm{~mL} / \mathrm{min} / 1.73 \mathrm{~m}^{2}$ & $72 / 360$ & 20.0 \\
\hline Diabetic foot with impaired VPT & $14 / 360$ & 3.9 \\
\hline Retinopathy requiring referral to specialist & $51 / 360$ & 14.2 \\
\hline \multicolumn{3}{|l|}{ Insulin status } \\
\hline On insulin & $46 / 360$ & 12.8 \\
\hline
\end{tabular}

Abbreviations: DM = diabetes mellitus; eGFR = estimated glomerular filtration rate; $\mathrm{HbA} I \mathrm{c}=$ glycosylated haemoglobin; $\mathrm{LDL}=$ low-density lipoprotein; $\mathrm{MDRD}=$ Modification of Diet in Renal Disease; VPT = vibration perception threshold 
different in the expected direction between patients with PIR and those without. Importantly, Q18, "Taking insulin causes family/friends to be more concerned" was originally designed to detect a negative view towards insulin use; however, more insulin-accepting patients agreed with the statement (Table 2).

The total C-ITAS scores, as described above, were higher among participants who refused insulin initiation $(42.42$ vs $35.78 ; t$ test, $\mathrm{P}<0.001)$. The testretest reliability for each question ranged from 0.294 to 0.725 , and 13 questions were significant $(\mathrm{P}<0.05)$. The test-retest reliability of the overall scores as defined above was $0.571(\mathrm{P}=0.002)$.

The EFA identified five factors with an eigenvalue of $>1$. Nonetheless, the scree plot correctly identified two factors within the questionnaire. When two factors were extracted using an Oblimin rotation, a few negative statements including Q18 were significantly associated with the other positive statements (Table 3). The three-, four-, and five-factor solutions were calculated as suggested by the eigenvalue, which did not provide better representation of the latent structure of ITAS.

In the EFA, the Kaiser-Meyer-Olkin measure of sampling adequacy was 0.834 and Bartlett's test of sphericity was significant $(\mathrm{P}<0.001)$, and signified adequate sample size for the test.

\section{Discussion}

Because the participants were old and not well educated, difficulties in answering the C-ITAS were expected. This assumption was further supported by the fact that the non-respondents were less educated and were older than the respondents. Nevertheless a high proportion of participants (89.8\%) were able to complete the entire questionnaire. Additional research might be necessary to assess the response rate if the questionnaire is self-administered because the staffing at our public out-patient clinics was limited. The use of ITAS might be limited if it cannot be self-administered because it was developed as a self-administered tool.

\section{Prevalence of psychological insulin resistance}

It is surprising that the prevalence of PIR was not as high as reported by previous studies. ${ }^{11,14}$ More than $50 \%$ of patients were willing to consider or accept insulin if suggested by their primary doctor. This finding might be because of differences in the patient cohorts or the improvements made to the PIR over the years due to patient education. Only 53 patients with DM out of the thousands of patients followed up in our clinic were started on insulin. Alternative reasons might explain the low rates of insulin use (eg

TABLE 2. The Chinese version of the Insulin Treatment Appraisal Scale (C-ITAS) score differences between patients with and without psychological insulin resistance (only statistically significant results are shown; $\mathrm{n}=3 \mid 4$ )

\begin{tabular}{|c|c|c|c|}
\hline & \multicolumn{3}{|c|}{ Willing to start insulin if advised?* } \\
\hline & Yes / will consider & No & $P$ value \\
\hline Total C-ITAS score & 35.78 & 42.42 & $<0.001$ \\
\hline Q3. Taking insulin prevents diabetes complications & $91.9 \%(159 / 173)$ & $83.7 \%(118 / 141)$ & 0.025 \\
\hline Q4. Others will see me as a sicker person & $67.1 \%(114 / 170)$ & $78.6 \%(110 / 140)$ & 0.024 \\
\hline Q5. Taking insulin makes life less flexible & $64.7 \%(112 / 173)$ & $83.0 \%(117 / 141)$ & $<0.001$ \\
\hline Q6. I am afraid of injecting myself with a needle & $69.6 \%(119 / 171)$ & $87.2 \%(123 / 141)$ & $<0.001$ \\
\hline Q7. Taking insulin increases hypoglycaemia & $70.8 \%(121 / 171)$ & $80.9 \%(114 / 141)$ & 0.04 \\
\hline Q8. Taking insulin improves health & $88.4 \%(153 / 173)$ & $80.0 \%(112 / 140)$ & 0.039 \\
\hline Q9. Insulin causes weight gain & $66.7 \%(114 / 171)$ & $77.1 \%(108 / 140)$ & 0.042 \\
\hline Q10. Insulin injections take a lot of time/energy & $52.0 \%(89 / 171)$ & $79.4 \%(112 / 141)$ & $<0.001$ \\
\hline Q11. Taking insulin means giving up activities I enjoy & $40.1 \%(69 / 172)$ & $62.9 \%(88 / 140)$ & $<0.001$ \\
\hline Q12. Taking insulin will worsen health & $60.6 \%(103 / 170)$ & $75.0 \%(105 / 140)$ & 0.007 \\
\hline Q13. Injecting is embarrassing & $41.3 \%(71 / 172)$ & $61.9 \%(86 / 139)$ & $<0.001$ \\
\hline Q14. Injecting insulin is painful & $62.8 \%(108 / 172)$ & $81.6 \%(115 / 141)$ & $<0.001$ \\
\hline Q15. It is difficult to inject correctly every day & $67.1 \%(116 / 173)$ & $83.7 \%(118 / 141)$ & 0.001 \\
\hline Q16. Taking insulin hinders fulfilling my responsibilities & $49.7 \%(86 / 173)$ & $73.8 \%(104 / 141)$ & $<0.001$ \\
\hline Q17. Taking insulin means better glucose control & $95.3 \%(164 / 172)$ & $84.4 \%(119 / 141)$ & 0.001 \\
\hline Q18. Taking insulin causes family/friends to be more concerned & $84.9 \%(146 / 172)$ & $65.2 \%(92 / 141)$ & $<0.001$ \\
\hline Q19. Taking insulin improves energy level & $87.3 \%(151 / 173)$ & $70.9 \%(100 / 141)$ & $<0.001$ \\
\hline
\end{tabular}

* Percentages of respondents who answered 'agree' or 'neutral' to these questions; denominators within the same group vary because missing data were excluded from calculation 
TABLE 3. Results of the exploratory factor analysis for Insulin Treatment Appraisal Scale using two factors (only factor loading $>0.3$ are shown)

\begin{tabular}{|c|c|c|}
\hline & \multicolumn{2}{|c|}{ Component } \\
\hline & 1 & 2 \\
\hline Use of insulin means control of diabetes failed & & 0.450 \\
\hline Use of insulin means my diabetes is worsened & & 0.408 \\
\hline Insulin can prevent diabetes complications & & 0.441 \\
\hline Use of insulin will make others view me as having more severe illness & 0.302 & \\
\hline Use of insulin makes life inflexible & 0.553 & \\
\hline I am afraid of injecting myself & 0.508 & \\
\hline Use of insulin will increase hypoglycaemia & 0.402 & \\
\hline Insulin can improve my health & & 0.627 \\
\hline Insulin will increase weight & 0.401 & \\
\hline Insulin use will consume time and energy & 0.720 & \\
\hline Insulin use means I have to give up my hobbies & 0.613 & \\
\hline Use of insulin means my health will deteriorate & 0.513 & \\
\hline Use of insulin is embarrassing & 0.585 & \\
\hline Insulin injection is painful & 0.516 & \\
\hline It is difficult to inject insulin correctly & 0.717 & \\
\hline Use of insulin means difficulty in fulfilling my responsibilities & 0.743 & \\
\hline Insulin can improve diabetes control & & 0.687 \\
\hline Insulin will make my family and friends more concerned & & 0.416 \\
\hline Use of insulin will increase my energy & & 0.534 \\
\hline Use of insulin will make me more dependent on my doctor & & \\
\hline
\end{tabular}

* Values not available because loading factor $<0.3$

physician beliefs and competencies regarding the use of insulin), and might merit additional research.

\section{Validity and reliability of the questionnaire}

The C-ITAS was reliable because it yielded high Cronbach's alpha scores (0.738-0.812) and correctly provided a higher score for patients who resisted insulin use. It identified many different attitudes towards insulin use; in the current study, answers to 17 out of 20 of the C-ITAS items significantly differed between patients who resisted insulin and those who did not, whereas a previous study showed that only four questions were able to make this distinction. ${ }^{12}$ This may be because individual patients had multiple concerns and many different attitudes towards insulin use.

Although the test-retest reliability value of all ITAS items was positive, the values were low, ranging from 0.294 to 0.725 for individual C-ITAS questions. In the present study, the C-ITAS was completed either via a personal interview with a research assistant or by self-administration. Retests were administered via telephone interviews by either the research assistant or the principal investigator. Therefore, the low test-retest reliability scores might be because of the different means of administration or due to the different interviewers. Conversely, this difference might reflect the actual low testretest reliability of the current C-ITAS that requires additional validation.

Question 18, "Taking insulin causes family/ friends to be more concerned", merits additional discussion. Originally designed as a negative statement, it is expected that patient resistance to insulin would positively predict the score. The reverse was true, however, in the current study (Table 2). When the statement was reviewed by six family physicians and one psychiatrist, the word "concerned" (關心) was translated into a word in Chinese that can also mean "caring" (使用胰島素 使家人和朋友對我更關心). It is likely that patients understood the question as, "Taking insulin causes my family and friends to be more caring toward me". Because Q18 was meant to be a negative statement, it is more appropriate to translate its meaning to "worry". This supposition is supported by both the Cronbach's alpha analysis, in which exclusion of Q18 improved the value of Cronbach's alpha, and the factor analysis, where Q18 was regarded as a factor with the other positive statements. The factor 


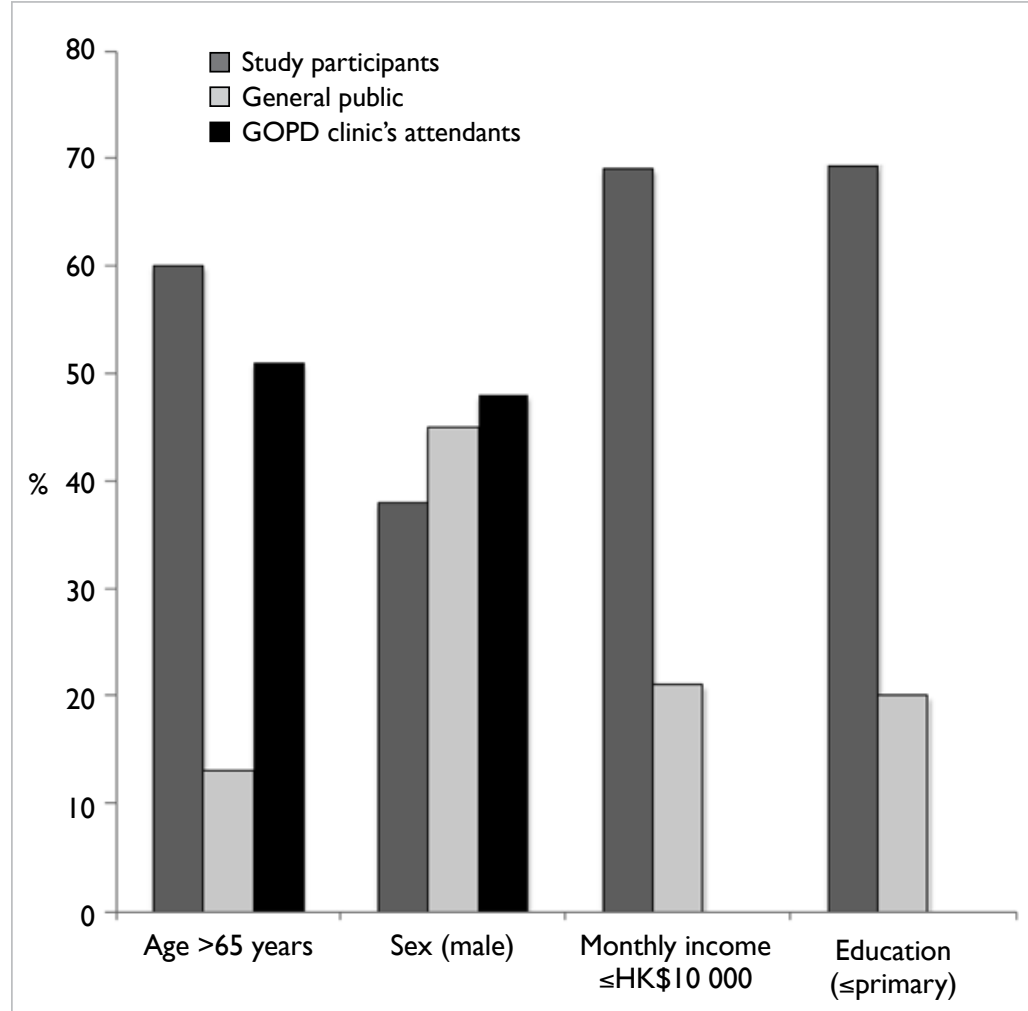

FIG 2. Comparison of demographic data in 2013

Abbreviation: GOPD = general out-patient department their disease as having deteriorated so that additional intervention is necessary.

This study was conducted in a major government-funded clinic in Hong Kong, and the demographics of the participants were more similar to those of other government clinics than to the general population (Fig 2). The extent to which the results can be generalised to other countries and to other social classes (eg wealthy patients attending private primary clinics) is not known.

A majority of the patients in the current study were insulin-naïve. Despite including all available insulin users in the clinic, the number of insulin users was small, and limits the potential applicability of this study's results to secondary or tertiary care where many patients may be on insulin.

The study also did not distinguish between questionnaires that were completed with the help of research staff and those that were self-administered. The influence of different administration methods on the outcome has not been previously described. For example, when participants did not understand a statement, the trained research assistant may use her own words to elaborate and explain it to the participant and thus may alter the statement's original sentence structure or intended meaning.

Another weakness was that data on macrovascular complications were not collected. Microvascular complications were well documented during the DM complication screening and were easily traceable. The tracing of macrovascular complications, however, was difficult because diagnostic coding needed to be entered or the complication needed to be mentioned in the latest case record by the respective doctors, and missed coding for macrovascular complications was not uncommon.

\section{Conclusions}

The prevalence of PIR was $44.9 \%$ in our population, which is less than that previously estimated. Tools such as the C-ITAS can improve physician's understanding of patient views on insulin and might help physicians to appropriately counsel their patients. The C-ITAS may provide clues to patients' knowledge about insulin use, eg the risk of hypoglycaemia or the side-effects of obesity. Despite good psychometric properties such as high internal consistency, there is a translation issue in at least one of the 20 statements. Health care professionals who wish to use the C-ITAS clinically should be aware of the instrument's limitations.

\section{Acknowledgements}

The author expresses gratitude to Prof Sandra Chan for her teaching and guidance regarding this research; to Prof Samuel Wong for his kind and 
timely advice; and to Drs YK Yiu and SN Fu and the Department of Family Medicine, Kowloon West Cluster, HK for their research support. The author would like to thank Ms Man-ping Chang and her team for the development of the C-ITAS and for allowing the use of the C-ITAS in the current study.

\section{Declaration}

The author has disclosed no conflicts of interest.

\section{References}

1. International Diabetes Federation. IDF diabetes atlas update 2012. Available from: http://www.idf.org/sites/ default/files/EN_6E_Atlas_Full_0.pdf. Accessed $1 \mathrm{Apr}$ 2013.

2. Hong Kong Department of Health. Hong Kong reference framework for diabetes care for adults in primary care settings. Available from: http://www.pco.gov.hk/english/ resource/professionals_diabetes_pdf.html. Accessed 1 Apr 2013.

3. Genuth S, Eastman R, Kahn R, et al. Implications of the United Kingdom prospective diabetes study. Diabetes Care 2003;26 Suppl 1:S28-32.

4. Davis TM, Colagiuri S, United Kingdom Prospective Diabetes Study. The continuing legacy of the United Kingdom Prospective Diabetes Study. Med J Aust 2004;180:104-5.

5. ADVANCE Collaborative Group, Patel A, MacMahon $\mathrm{S}$, et al. Intensive blood glucose control and vascular outcomes in patients with type 2 diabetes. N Engl J Med 2008;358:2560-72.

6. Riddle $\mathrm{MC}$, Yuen $\mathrm{KC}$. Reevaluating goals of insulin therapy: perspectives from large clinical trials. Endocrinol Metab Clin North Am 2012;41:41-56.

7. Action to Control Cardiovascular Risk in Diabetes Study Group, Gerstein HC, Miller ME, et al. Effects of intensive glucose lowering in type 2 diabetes. $\mathrm{N}$ Engl J Med 2008;358:2545-59.

8. ACCORD Study Group, Gerstein HC, Miller ME, et al. Long-term effects of intensive glucose lowering on cardiovascular outcomes. N Engl J Med 2011;364:818-28.

9. Turner RC, Cull CA, Frighi V, Holman RR. Glycemic control with diet, sulfonylurea, metformin, or insulin in patients with type 2 diabetes mellitus: progressive requirement for multiple therapies (UKPDS 49). UK Prospective Diabetes Study (UKPDS) Group. JAMA 1999;281:2005-12.

10. Rubino A, McQuay LJ, Gough SC, Kvasz M, Tennis P. Delayed initiation of subcutaneous insulin therapy after failure of oral glucose-lowering agents in patients with type 2 diabetes: a population-based analysis in the UK. Diabet Med 2007;24:1412-8.

11. Wong S, Lee J, Ko Y, Chong MF, Lam CK, Tang WE. Perceptions of insulin therapy amongst Asian patients with diabetes in Singapore. Diabet Med 2011;28:206-11.

12. Woudenberg YJ, Lucas C, Latour C, Scholte op Reimer WJ. Acceptance of insulin therapy: a long shot? Psychological insulin resistance in primary care. Diabet Med 2012;29:796-
802.

13. Jenkins N, Hallowell N, Farmer AJ, Holman RR, Lawton J. Participants' experiences of intensifying insulin therapy during the Treating to Target in Type 2 diabetes (4-T) trial: qualitative interview study. Diabet Med 2011;28:543-8.

14. Yiu MP, Cheung KL, Chan KW, et al. A questionnaire study to analyze the reasons of insulin refusal of DM patients on maximum dose of oral hypoglycemic agents (OHA) among 3 GOPCs in Kowloon West Cluster. 2010. Available from: http://www.ha.org.hk/haconvention/ hac 2010/proceedings/pdf/Poster/spp-p5-38.pdf. Accessed 1 Apr 2013.

15. Chen CC, Chang MP, Hsieh MH, Huang CY, Liao LN, Li TC. Evaluation of perception of insulin therapy among Chinese patients with type 2 diabetes mellitus. Diabetes Metab 2011;37:389-94.

16. Fu SN, Chin WY, Wong CK, et al. Development and validation of the Chinese Attitudes to Starting Insulin questionnaire (Ch-ASIQ) for primary care patients with type 2 diabetes. PLoS One 2013;8:e78933.

17. Ma GX. Between two worlds: the use of traditional and western health services by Chinese immigrants. J Community Health 1999;24:421-37.

18. Lai WA, Lew-Ting CY, Chie WC. How diabetic patients think about and manage their illness in Taiwan. Diabet Med 2005;22:286-92.

19. Martin A, Rief W, Klaiberg A, Braehler E. Validity of the Brief Patient Health Questionnaire Mood Scale (PHQ-9) in the general population. Gen Hosp Psychiatry 2006;28:71-7.

20. Peyrot M, Rubin RR, Khunti K. Addressing barriers to initiation of insulin in patients with type 2 diabetes. Prim Care Diabetes 2010;4 Suppl 1:S11-8.

21. Brod M, Kongsø JH, Lessard S, Christensen TL. Psychological insulin resistance: patient beliefs and implications for diabetes management. Qual Life Res 2009;18:23-32.

22. Snoek FJ, Skovlund SE, Pouwer F. Development and validation of the insulin treatment appraisal scale (ITAS) in patients with type 2 diabetes. Health Qual Life Outcomes 2007;5:69.

23. Chang MP, Huang CY, Li TC, Liao LN, Chen CC. Validation of the Chinese version of the insulin treatment appraisal scale. J Diabetes Investig 2010;1(Suppl 1):88.

24. Hermanns N, Mahr M, Kulzer B, Skovlund SE, Haak T. Barriers towards insulin therapy in type 2 diabetic patients: results of an observational longitudinal study. Health Qual Life Outcomes 2010;8:113.

25. World Health Organization. About diabetes 2013. Available from: http://www.who.int/diabetes/action_online/basics/ en/index1.html. Accessed 1 Feb 2013.

26. Chow KM, Chan CW, Choi KC, et al. Psychometric properties of the Chinese version of Sexual Function After Gynecologic Illness Scale (SFAGIS). Support Care Cancer 2013;21:3079-84.

27. Tang DY, Liu AC, Leung MH, Siu BW. Antisocial Personality Disorder Subscale (Chinese version) of the Structured Clinical Interview for the DSM-IV Axis II disorders: validation study in Cantonese-speaking Hong Kong Chinese. East Asian Arch Psychiatry 2013;23:37-44. 